\title{
Itinerário Terapêutico de Mulheres com Câncer do Colo do Útero: uma Abordagem Focada na Prevenção
} Therapeutic Itinerary of Women with Cervical Neoplasms: an Approach Focused on Prevention

\author{
Itinerario Terapéutico de Mujeres con Cáncer de Cuello Uterino: un Enfoque \\ Centrado en la Prevención
}

Maria das Graças Martins Ribeiro', Sueli Maria dos Reis Santos², Maria Teresa Bustamante Teixeira ${ }^{3}$

\section{Resumo}

Introdução: $\mathrm{O}$ Brasil tem realizado esforços crescentes para melhorar a eficiência dos programas de prevenção do câncer do colo do útero, visando à modificaçáo das altas taxas de incidência e mortalidade por esse tipo de câncer, entretanto as medidas adotadas não têm obtido os resultados esperados. Objetivo: $\mathrm{O}$ estudo teve como objetivo analisar o itinerário terapêutico de mulheres com câncer do colo do útero focando a prevençấo. Método: Foi adotado, como percurso metodológico, a abordagem qualitativa e o método "História de Vida", mediante entrevista aberta. As entrevistadas foram mulheres em tratamento para o câncer do colo do útero em um hospital especializado no tratamento do câncer, localizado em um município de Minas Gerais. Os dados foram analisados após categorização temática. Resultados: Evidenciaram-se diversos motivos que levaram a maioria das mulheres a não realizar a prevenção. Entre eles, ressaltase o conceito que emergiu de saúde, doença e prevenção, o desconhecimento sobre o exame preventivo, os fatores culturais e sociais frente a questóes de gênero, a qualidade dos atendimentos e organização dos serviços de saúde. Conclusáo: Percebe-se que a questão de prevenção não é simplesmente uma escolha, mas uma decisão envolvendo emoçóes, experiências, conhecimento e circunstâncias, mediadas pelo contexto social, cultural, político, econômico e por avaliaçôes das respostas obtidas no serviço, sendo realizada entre as possibilidades acessíveis.

Palavras-chave: Atenção à Saúde; Saúde da Mulher; Prevenção de Câncer de Colo Uterino; Epidemiologia Descritiva

\footnotetext{
${ }^{1}$ Doutoranda do Curso de Pós-Graduação em Saúde da Faculdade de Medicina da Universidade Federal de Juiz de Fora. Professora Adjunta da Faculdade de Enfermagem da Universidade Federal de Juiz de Fora. E-mail: mariagmribeiro@yahoo.com.br.

${ }^{2}$ Doutora em Comunicação e Cultura. Professora Associada da Faculdade de Enfermagem da Universidade Federal de Juiz de Fora. E-mail: sueli.santos@uff.edu.br.

${ }^{3}$ Doutora em Saúde Coletiva. Professora Associada da Faculdade de Medicina da Universidade Federal de Juiz de Fora. E-mail: teitabt@hotmail.com.

Endereço para correspondência: Maria das Graças Martins Ribeiro. Sítio N. Sra. Das Graças, Caixa Postal 8. Rio Novo (MG), Brasil. CEP: $36150-000$.
} 


\section{INTRODUÇÃO}

Os dados mundiais apontam o câncer do colo do útero como responsável pela morte de 230 mil mulheres por ano, com uma estimativa para 2010/2011 de surgimento de 500 mil casos novos por ano ${ }^{1}$. No Brasil, ocorrerão 18.430 casos novos de câncer do colo do útero, com um risco estimado de 18 casos a cada 100 mil mulheres, constituindo-se em um problema de saúde pública. $\mathrm{O}$ câncer mais frequente entre as mulheres é o de mama, enquanto o do colo do útero assume a segunda posição ${ }^{1}$.

A incidência desse tipo de câncer pode ocorrer na faixa etária de 20 a 29 anos, e o risco aumenta, rapidamente, a partir dos 35 anos, até atingir seu pico geralmente na faixa etária de 45 a 49 anos $^{1}$. Está entre as principais causas de morte da populaçáo feminina de 40 a 60 anos, gerando custos sociais de repercussão familiar e na economia do país, interrompendo a vida de um grande contingente de mulheres em idade útil, social e economicamente ativa ${ }^{2-4}$.

No Brasil, o exame citopatológico (teste de Papanicolaou) é recomendado como estratégia de rastreamento, para mulheres a partir de 25 anos, que já iniciaram atividade sexual, prosseguindo até os 64 anos de idade e serem interrompidos após essa idade quando tiverem pelo menos dois exames negativos consecutivos nos últimos cinco anos. O intervalo entre os exames deve ser de três anos, após dois exames anuais consecutivos considerados normais ${ }^{5}$.

Estratégias para a prevenção do câncer do colo do útero surgiram no Brasil, de forma mais organizada, em 1984, com o Programa de Atenção Integral à Saúde da Mulher (PAISM). Observou-se uma crescente ampliação da oferta de exames citopatológicos, a partir de 1998, com o Programa Viva Mulher, que foi precedido por um projeto-piloto em 1996. Antes de 1998, o número de exames não ultrapassava sete milhóes por ano e no período de 2003 e 2004 foram realizados 10,4 milhóes. No Brasil, os dados quanto à cobertura são escassos, porém dois estudos de base populacional com abrangência nacional ocorridos em 2003 apresentaram coberturas de menos de $70 \%$ nos últimos três anos ${ }^{6}$.

Para a Organização Mundial da Saúde (OMS), uma cobertura de $80 \%$ do exame entre mulheres de 35 a 59 anos seria suficiente para impactar os indicadores de incidência e mortalidade ${ }^{7}$ o que pode ser observado após quatro anos de implementação das ações de rastreamento e cerca de dois anos mais tarde respectivamente ${ }^{8}$. Em uma pesquisa realizada em um município do nordeste brasileiro, observou-se que algumas mulheres realizavam o exame com intervalos muito curtos, diferentemente do recomendado, o que pouco contribui para a prevenção, entretanto eleva o custo e dificulta o acesso dos grupos mais vulneráveis ${ }^{4}$. Destaca-se que grande parte dos exames citopatológicos é realizada em mulheres com menos de
35 anos de idade que buscam os serviços de saúde para a atenção reprodutiva, enquanto o risco aumenta a partir dessa idade?

Apesar de os esforços crescentes para melhorar a eficiência dos programas de prevenção, ou seja, aumentar o quantitativo de mulheres examinadas com qualidade e com o menor custo possível, a manutenção das taxas de incidência e de mortalidade no Brasil revela que as medidas adotadas não conduziram aos resultados esperados ${ }^{3}$.

Estudos envolvendo mulheres tentaram revelar as causas que obstaculizam a efetivação do exame de Papanicolaou, porém poucos abordaram mulheres com diagnóstico de câncer do colo do útero. Sabe-se que as mulheres, diante da constataçáo da doença, têm maior possibilidade para refletir sobre o caminho percorrido ou não na prevenção, o que fortalece a proposta do presente estudo. Nesse sentido, optou-se por trabalhar com o itinerário terapêutico dessas mulheres, entendido como eventos sucessivos que, formando um percurso, caracterizam a forma como o sujeito elabora ou define a sua situação dentro de um dado fenômeno sociocultural ${ }^{10}$.

Assim, o estudo teve como objetivo analisar o itinerário terapêutico de mulheres com câncer do colo do útero focando a prevenção.

\section{MÉTODO}

Foi realizado um estudo descritivo, com abordagem qualitativa. Na pesquisa qualitativa,

busca-se a compreensão particular daquilo que se estuda [...] a generalização é abandonada e o foco da sua atenção é centrado no específico, no individual, almejando sempre a compreensão e não a explicação dos fenômenos estudados ${ }^{11}$.

O método utilizado foi a História de Vida que usa a história de uma vida ou parte dela, narrada ao entrevistador, tal qual foi vivenciada pelo sujeito, possibilitando encontrar o ponto de convergência ou divergência dos seres humanos em suas condiçóes sociais, da cultura e da práxis, assim como as relaçóes socioestruturais e da dinâmica histórica ${ }^{12}$.

A pesquisa foi aprovada no Comitê de Ética da Universidade Federal de Juiz de Fora, parecer número 012/2008, atendendo à Resolução 196/1996.

Os sujeitos foram mulheres que buscaram tratamento para o câncer do colo do útero, em um hospital filantrópico, conveniado ao Sistema Único de Saúde (SUS) e localizado em um município de médio porte, pertencente ao Estado de Minas Gerais. Esse hospital atende especificamente a pessoas com câncer, registrando um número significativo de atendimentos às mulheres com câncer do colo do útero, muitas vezes, em estadiamentos avançados. Essas 
mulheres são procedentes do próprio município e ou de municípios pactuados para procedimentos de média e alta complexidade.

A instituição forneceu os dados das mulheres a partir da agenda de marcação de consultas, com objetivo de verificar data e horário de retorno. A pesquisadora compareceu nas datas, no período de janeiro a abril de 2009, identificou as mulheres na sala de espera e as convidou a fazer parte do estudo.

Os critérios de inclusão foram mulheres com diagnóstico de câncer do colo do útero, em qualquer fase do tratamento, atendidas no referido serviço no período de coleta de dados. Realizou-se, através dos prontuários, um levantamento de dados referentes à caracterização das mulheres, tais quais: idade, escolaridade, renda familiar, situação conjugal, religião, número de filhos, procedência, assim como estadiamento e tratamento.

Conforme preconizado pelo Método "História de Vida", solicitou-se às mulheres que falassem livremente sobre a sua vida, no que fosse relacionado à prevençáo do câncer do colo do útero. Os relatos foram obtidos por meio de entrevista aberta, gravada e transcrita pela pesquisadora. Assim que os depoimentos relacionados ao objeto da pesquisa começaram a se repetir, interromperam-se as entrevistas. Esse ponto de saturação ocorreu na décima entrevista.

Após as transcriçóes e leitura aprofundada das entrevistas, foram realizadas a identificação e classificação dos temas, que emergiram nos depoimentos, destacando a prevenção e o itinerário em busca da mesma. Como produto da classificação foi evidenciado quatro temas significativos, que foram analisados com base em referências atuais sobre a temática em questão.

Para manter o sigilo e anonimato das participantes do estudo, os fragmentos das falas foram referenciados com a palavra Mulher, seguida de numeração arábica.

\section{RESULTADOS E DISCUSSÃO}

Este estudo considerou a prevenção apenas o exame colpocitológico, ou teste de Papanicolaou, pois percebeuse que as mulheres associaram a prevenção exclusivamente ao "exame preventivo", terminologia adotada a partir da coleta dos depoimentos.

As entrevistadas tinham idade entre 46 e 74 anos, sendo que oito mulheres estavam na faixa etária dos 50 aos 60 anos de idade. Somente uma possuía o ensino fundamental completo, enquanto as demais relataram possuir o ensino fundamental incompleto. Quanto à renda familiar, cinco mulheres recebiam dois salários mínimos mensais enquanto as outras auferiam uma renda de um salário mínimo por mês.

Observando a situação marital, duas eram viúvas, uma divorciada e sete eram casadas. A maioria era multípara, com cerca de 5-6 filhos, mas dois extremos foram identificados, sendo uma com um filho e outra com dez filhos. Salienta-se que, em relação à espiritualidade, crença e religiâo, duas eram evangélicas e oito católicas.

Somente duas mulheres eram oriundas de outros municípios, as demais eram moradoras do município onde se localiza o hospital cenário deste estudo.

Quanto ao estadiamento, três mulheres estavam no estádio Ib, três foram diagnosticadas com a classificação estádio IIb, enquanto quatro se encontravam com as lesôes características do estádio $\mathrm{IIIb}^{13}$. Todas as mulheres foram submetidas à quimioterapia, radioterapia e braquiterapia.

As mulheres, ao falarem livremente sobre o tema proposto, relataram a periodicidade com que realizavam o exame preventivo, até a data do diagnóstico do câncer. Entre as dez mulheres do estudo, sete disseram nunca terem realizado o preventivo. Entre as três que relataram já terem feito o preventivo, uma o realizou uma única vez, outra o realizou duas vezes na vida, enquanto a terceira o fazia anualmente.

A partir da análise dos depoimentos, foi possível destacar quatro categorias: um caminho tecido pelo desconhecimento; um caminho tecido pelas oportunidades; um caminho tecido pelo gênero; um caminho tecido pelos serviços de saúde.

\section{UM CAMINHO TECIDO PELO DESCONHECIMENTO}

As entrevistadas demonstraram desconhecimento da condição assintomática do câncer do colo do útero em seus estágios iniciais, assim como insuficiência no conhecimento sobre o exame preventivo, sua finalidade, periodicidade e população-alvo. O conceito de saúde emergiu como ausência de perturbação física e ou psíquica e ligada a ter disposição. Evidenciou-se uma ausência de percepção de risco.

Eu fiz preventivo só uma vez na vida..., porque nunca tive nada, nada mesmo, era muito disposta. Não pensava que eu ia ter [...] (mulher 1).

[...] eu não fazia preventivo. Ah! Eu achava que num precisava. Não sentia nada (mulher 2).

Só fiz preventivo duas vezes. Nunca pensei que ia ter (mulher 3).

Esses relatos remetem a uma questão mais ampla e complexa, que se referem à própria construção cultural do significado dos fenômenos de saúde e doença pelos indivíduos e coletividades. A doença tenderia a ser percebida somente quando houvesse uma incapacitação do desempenho social, representada principalmente pelo trabalho ${ }^{14}$.

Detectar doença assintomática é um fenômeno comum na área da saúde devido ao avanço do conhecimento que 
aperfeiçoa amiúde a tecnologia diagnóstica. Entretanto, embora processos patológicos possam estar presentes no corpo, sem que se tenha conhecimento, serão consideradas enfermidades quando se tornam sensíveis ao doente.

A saúde e a doença constituem uma interpretação do indivíduo da sua subjetividade, porém formada a partir de processos de definição e interpretação construídos intersubjetivamente ${ }^{15}$. Embora essa interpretação seja pessoal, é baseada em significados internalizados através de interação e trocas em processo de comunicação com outras pessoas e construídos na vida cotidiana, refletindo a sabedoria popular, as experiências individuais e coletivas, as características da cultura local e também concepçôes atuais e pregressas da classe médica, entre outras influências.

Em um estudo, entre mulheres que relataram nunca terem realizado o exame preventivo, 45,3\% justificaram não achar necessário, porque não tinham sintomas de problemas ginecológicos e ou se consideravam saudáveis ${ }^{16}$.

Alguns profissionais de saúde acabam por reforçar esse tipo de comportamento, que liga a necessidade do exame preventivo a queixas, conforme depoimento abaixo:

A Dra. [...] falou pra mim que eu tava com um pouquinho de corrimento e entáo depois era pra mim voltar lá pra fazer o preventivo (mulher 5).

Habitualmente, diante de queixas como leucorreia, prurido, e outras queixas ginecológicas, as mulheres são orientadas a marcar um exame preventivo, pois o mesmo também se presta ao diagnóstico de algumas patologias do trato genital inferior. A indicação do exame preventivo perante queixas ginecológicas pode originar a crença de que esse exame está relacionado à condição sintomática de uma enfermidade.

Estudos realizados em Fortaleza e em São Paulo revelaram que $33,3 \%$ e $18,2 \%$ das mulheres, respectivamente, relataram a presença de queixas ginecológicas como principal motivo para a realizaçáo do último exame preventivo ${ }^{16-17}$. O desconhecimento sobre o exame preventivo, sua periodicidade, finalidade, população-alvo fica claro em alguns depoimentos:

Nas campanhas eu não fiz, eu achei que já tava velha pra isto, que num precisava fazer mais, porque já tava na menopausa (mulher 3).

[...] tive que falar prá minha filha e ela falou: mãe, a senhora não tava fazendo preventivo? Eu falei, tava minha filha, tinha seis anos que eu tinha feito e num deu nada, até procurei o resultado pra mostrar pra ela (mulher 3).

A atenção à saúde da mulher tinha como foco o acompanhamento dos eventos relacionados à gravidez, parto, puerpério, contracepção e ciclo menstrual. Após a menopausa, esse foco é direcionado às alteraçóes próprias do climatério, que podem vir acompanhadas de intensa sintomatologia e outros problemas de saúde como alteraçôes cardiovasculares, hipertensão, diabetes, artralgias, dores lombares e outros, demandando atendimento nos serviços de saúde, em virtude de suas queixas específicas. A prevenção de agravos relacionados aos órgãos genitais (internos e externos) é negligenciada e relegada ao segundo plano e até mesmo esquecida, na ausência de queixas.

As campanhas, mutiróes e a educação em saúde são estratégias usadas para a melhoria das condiçôes de saúde da população. Entretanto, pode ocorrer ruído de comunicação e estratégias pouco adequadas por ocasiāo das campanhas, assim como na prática da educação em saúde, possibilitando que as mensagens sejam processadas de forma incompleta ou ininteligível para as mulheres.

O desconhecimento sobre a finalidade, periodicidade do exame preventivo resulta numa despreocupação e desinteresse pela sua busca, enquanto a apropriação desses conhecimentos acarreta uma maior e mais consciente procura pela prevenção ${ }^{18}$.

Um estudo realizado em São Paulo revelou que 2,5\% das mulheres que náo realizaram o exame preventivo alegaram desconhecimento de sua importância e finalidade ${ }^{16}$.

A prevenção do câncer do colo do útero é considerada prioridade nacional, inserida no Programa Nacional de Controle do Câncer do Colo do Útero e Mama, ratificada no Pacto pela Saúde 2006, e prevê ação educativa direcionada às mulheres propiciando informaçóes sobre a saúde e o câncer. Em Minas Gerais, onde está localizada a cidade, cenário do estudo, está contemplada nos protocolos de atenção à saúde da mulher ${ }^{5-19}$.

O Sistema de Informação do Câncer do Colo do Útero (SISCOLO)/SUS volta-se para o registro de procedimentos e não para o usuário, controlando diversas variáveis, mas não permitindo o registro da história de rastreamento das mulheres de forma longitudinal identificando data do último exame, alteraçóes e busca do resultado, mulheres expostas a risco e sem controle a mais de três anos. Nas equipes, em que há o Agente Comunitário de Saúde, este poderia realizar a busca ativa mediante a existência de um registro na Unidade de Atenção Primária à Saúde (UAPS) baseado na pessoa ${ }^{20}$.

Considerando a carência de informatização dos serviços e tomando como exemplo o Programa Nacional de Imunização (PNI), no qual as açôes programadas são monitoradas por meio do cartáo do usuário e o cartão espelho arquivado no serviço, o programa de prevenção do câncer do colo do útero, nas UAPS, poderia adotar essa sistemática. Essa ação propiciaria a agilidade na convocação para exame, identificação de faltosas e reconvocação, recebimento dos laudos, identificação das 
mulheres com resultados positivos ao rastreamento para vigilância do caso, orientaçáo e encaminhamento das mulheres para unidade secundária, avaliação da cobertura de citologia na área.

\section{UM CAMINHO TECIDO PELAS OPORTUNIDADES}

Quando a prevenção foi realizada, ocorreu mediante o surgimento de uma oportunidade ou chance, conforme depoimento que se segue:

Fiz o preventivo só duas vezes na minha vida, há muito tempo: A $1^{\text {a }}$ foi naquele negócio de mutiráo. A $2^{\text {a }}$ vez foi quando a minha nora tava fazendo tratamento pra engravidar, marcou preventivo pra ela e aproveitou e marcou pra mim também [...] (mulher 3).

Percebe-se que a realização do exame pode estar mais relacionada à conveniência ou chance de realizá-lo durante campanhas, mutiróes, ou incentivo de outras pessoas, que propriamente mediante um caráter espontâneo baseado em percepçáo de risco ou pela valorização de medidas preventivas. Considerando o valor das oportunidades, os profissionais de saúde devem aproveitá-las em seus contatos com as mulheres. Entretanto, alguns, negligenciando o atendimento, nem sempre realizam a coleta do material cervical para ser examinado.

A Dra. [...] falou pra mim que depois que eu ganhasse nenê que era pra mim voltar lá pra fazer o preventivo (mulher 5).

O Ministério da Saúde (MS) recomenda a realização do exame preventivo nas gestantes, obedecendo à periodicidade e faixa etária das demais mulheres, sendo que a procura ao serviço para realizar o pré-natal deve ser considerada uma oportunidade para o rastreio ${ }^{5}$. É uma questáo de diminuir-lhes a necessidade de vindas repetidas e garantir a prevenção.

Sabe-se que as mulheres têm presença acentuada nas unidades de saúde buscando os serviços por diversos motivos, inclusive pelo seu papel de cuidadora da família. Os profissionais de saúde devem otimizar sua presença examinando sua situação em relação ao exame preventivo e reforçando a necessidade da prevenção.

Muitas mulheres fazem o preventivo aproveitando os momentos de consulta por razóes diversas que não a prevenção, caracterizando um rastreamento oportunístico conforme alguns autores observaram em seus estudos ${ }^{3-20}$, o qual, ainda que não seja o ideal para concretizar a efetividade de um programa, não pode ser uma oportunidade perdida. A desorganização nos serviços contribuiu para um caminho no qual as oportunidades se perderam:
Aí fui lá consultar. Ela fez o exame e pediu uma porção de exames. Eu fiz e quando fui buscar os resultados, disse que num tinha encontrado, num tava achando, perdeu meus exames. Fui lá umas três vezes e nada. Ninguém achou meus exames. Aí fui larguei aquilo pra lá [...] (mulher 4).

Quando eu fiz o preventivo naquele negócio de mutirão, falaram que era pra pegar o resultado no posto. Fui lá uma porção de vezes e falaram que num tinha nada lá não. Aí num sei o que deu [...] (mulher 3).

Estudos realizados em Fortaleza, em 2004 $4^{21}$, e, em São Paulo, em $2000^{16}$, concluíram que 8,97\% e 13\%, respectivamente, das mulheres não retornam em busca do resultado, pelos mais diversos motivos. Não se observou esse comportamento no estudo. Ainda que poucos preventivos tenham sido realizados, houve uma busca pelo resultado, ocorrendo falhas nos serviços que comprometeram o acesso.

Os serviços de saúde, em qualquer dos seus níveis, apresentam estruturas administrativas complexas, nas quais devem ser armazenadas varias informaçóes a respeito dos usuários, tendo muitas destas necessidade de transitar entre os vários serviços.

A informatização promove um fluxo mais adequado das comunicaçóes, mas muitos serviços ainda utilizam de tecnologias ultrapassadas e se utilizam de papéis que circulam por vários caminhos.

$\mathrm{O}$ acesso a açóes e serviços de saúde tem sido considerado como um dos componentes principais na atenção à saúde. $\mathrm{O}$ aspecto sócio-organizacional da acessibilidade inclui os atributos referentes aos recursos e à organizaçáo do serviço, que podem facilitar ou dificultar os esforços do cliente em obter cuidados. A perda de resultados de exames traz grandes transtornos ao usuário, ocasionando perda de tempo, prejuízo financeiro, pelas vindas repetidas ao serviço na tentativa de encontrá-los, prejuízos emocionais ante à incerteza dos resultados, à expectativa e ao desagrado de ter de repeti-los. Isto gera descrédito na instituição e nos profissionais de saúde.

\section{UM CAMINHO TECIDO PELO GÊNERO}

O exame preventivo foi considerado algo temeroso por acarretar dor e constrangedor pela exposiçáo do corpo:

Quando cheguei pra fazer vi que marcaram pra mim errado, marcaram pro médico. Era pra ter marcado com a Dra. [...] Aí eu fiquei com vergonha e voltei pra casa e nunca mais fiz (mulher 5).

Eu num fazia preventivo, não. Eles falavam comigo pra fazer, mas eu tinha medo, medo de doer. Eles falavam comigo que doía e eu tinha medo (mulher 7). 
Com ou sem coleta de material cervicovaginal, o exame ginecológico é visto por muitas mulheres como uma experiência dolorosa, embaraçosa e desagradável. Retornando à faixa etária das mulheres do estudo, elas fazem parte de uma geração que sofreu intensamente os efeitos da repressão sexual. Os fatores culturais de desvalorização da feminilidade levam as mulheres ao desconhecimento do seu corpo e à vergonha de expô-lo ainda que seja por necessidade de se realizar algum exame.

As mulheres relatam umas às outras o significado do exame, significado este subjetivo, mas com poder de perpetuar e disseminar a convicçáo de que o exame preventivo fatalmente acarreta dor.

Os resultados encontrados são semelhantes aos de outros estudos, em que o exame foi considerado embaraçoso, desconfortável, ocasionando medo e ou vergonha ${ }^{16-17,22-23}$.

Esses sentimentos podem ser consequentes de experiências prévias negativas durante um exame ginecológico, efetuadas sem esclarecimento, de forma fria e descuidada, afetando o espaço de autoconhecimento do corpo e da sexualidade da mulher.

Estudos mostram que a realização do preventivo está diretamente ligada à condição socioeconômica das mulheres', e problemas no cotidiano do viver exigem enfrentamentos imediatos absorvendo o tempo, a atenção, o raciocínio, impedindo a visão de outras necessidades que se mostram menos prementes:

É que eu tinha muita luta, muito trabalho, muita dificuldade, uma filha especial. Muita pobreza. Eu vivia uma vida muito perturbada. Ele chegava em casa quebrando tudo, batendo nos filhos. Porque a gente tinha esses problemas ele descarregava na família. Era difícil fazer o exame com uma vida destas. Entáo fui deixando passar mesmo (mulher 3).

A luta pela sobrevivência, relacionamentos familiares conturbados afetam a saúde das pessoas por mobilizaremnas totalmente em direção a resolver necessidades primárias e prementes. As práticas de autocuidado podem ser secundárias pelas mulheres diante de uma sobrecarga de tarefas laborais que se superpóem envolvendo cuidados coma a família e o $\operatorname{lar}^{22}$. O nascimento de um filho especial pode trazer complicaçóes para o relacionamento do casal e da dinâmica familiar, ainda mais em situaçáo de pobreza. A manutenção do afeto e relacionamento conjugal não é tarefa fácil para o casal, dentro de um clima de culpabilização e decepção ${ }^{24}$.

É comum a mãe julgar que apenas ela é capaz de cuidar adequadamente e de dar afeto aos filhos. Essa ideologia tem suas raízes culturais no século passado, no modelo de família à época, e quando também se dizia que só a mãe poderia dar tudo o que o filho precisava para se desenvolver bem. A casa era identificada com a mulher e ela se dizia a 'dona da casa', sendo responsável por todos os afazeres do lar e cuidados dos filhos. Sua autoridade era doméstica, fundada na valorização da figura da mãe e esposa. A família era identificada com o homem e ele se dizia o chefe e provedor da mesma ${ }^{24}$. Salienta-se que uma transmissão cultural se processa dentro do próprio relacionamento mãe-filha. As mulheres da mesma maneira como foram educadas, educam suas filhas perpetuando a cultura do exercício da maternagem como atividade suprema e específica da mulher. Por outro lado, os filhos homens são educados para reduzir ou reprimir o desejo de exercer a maternagem, julgada como específica da mulher. Obviamente com esse tipo de formação as mulheres sentem-se mais responsáveis pela criação dos filhos ${ }^{24}$.

A violência de gênero, até recentemente um assunto marginal entre os temas da saúde, tem um impacto muito grande na saúde da mulher, sendo responsável por um em cada cinco anos potenciais de vida saudável perdidos, considerando-se apenas a violência sofrida na esfera doméstica ${ }^{24}$.

\section{UM CAMINHO TECIDO PELOS SERVIÇOS DE SAÚDE}

Um atendimento, distanciado da prática da integralidade, contribui para que a mulher não realizasse o preventivo:

Nunca nenhum médico falou pra eu fazer. Sabe, se a gente fala alguma coisa com eles que não é o que eles tratam, eles falam pra gente: oh! Isto náo é comigo não e não faz nada, nada, fica por isso mesmo (mulher 2).

[...] mas nunca nenhum médico falou que eu tinha que fazer, eu consultava e eles num falavam disto. Já consultei vários médicos, pra muitas coisas que tava sentindo, nunca os médicos falaram que eu precisava fazer preventivo (mulher 4).

Embora a coleta de preventivo não seja exclusiva do profissional médico, podendo ser feita pelo enfermeiro, as mulheres o referenciaram denotando uma visão ainda existente de centralidade do mesmo na atenção à saúde. Em um estudo realizado em Sáo Paulo, entre mulheres, sobre motivos relatados para a realização do último preventivo, a recomendação médica foi citada por $24,9 \%$ das mulheres.

É importante ressaltar que em observância ao princípio da integralidade, uma consulta médica, ou de outro profissional de saúde, por mais especializada que seja, não pode deixar de fazer uma escuta atentiva, vislumbrando identificar outras necessidades para as quais há saberes e práticas disponíveis na equipe e em outros serviços, que possam complementar a assistência ao usuário ${ }^{25}$. 
Salienta-se que a educação em saúde, acerca da prevenção do câncer do colo do útero, é uma atividade preconizada pelo MS. Dessa forma, a presença da mulher na unidade deve ser aproveitada por todos os integrantes $\mathrm{da}$ equipe, no sentido de orientá-las e incentivá-las a realizar o exame preventivo, não se constituindo responsabilidade de um único membro da equipe.

A única entrevistada, que relatou realizar o preventivo anualmente, o fez em desacordo à periodicidade recomendada pelo MS e às orientaçôes preconizadas pelas diretrizes do SUS, que estabelece uma linha-guia de cuidados em que a porta de entrada é preferencialmente a atenção primária, demonstrando a falta de credibilidade na unidade de saúde onde está cadastrada:

Eu fazia todo ano com o Dr. [...] lá no (nível secundário de atenção à saúde). Sempre dava normal, mas deste último não. No posto eu não faço não, não é a mesma coisa não. Demora a sair o resultado, acho que eles fazem aquilo de qualquer maneira, corrido. Imagine, eu fazia todo ano ali e ainda aconteceu isto! Imagina então pelo posto? Eu já tinha até morrido, não ia dar nada. Faz de qualquer maneira. Nunca fiz no posto, mas vejo os outros falar que é assim. Eu ia no posto só pra moça marcar a minha consulta lá (nível secundário) pra fazer o preventivo, depois pegava o resultado, ia no posto pra moça marcar outra consulta pra mostrar o resultado (mulher 6).

Ainda em busca de atendimento de melhor qualidade, até se dispóem a despender recursos financeiros significativos perante a sua condição econômica:

[...] eu tava esperando me aposentar pra fazer um check-up geral, porque a gente vai pro SUS, não é que eles sâo ruins, os médicos, mas eles não podem fazer o justo, eles não ganham pra isto, então eles atendem da altura que pode. Coitados (mulher 3).

A falta de investimentos em educação permanente, recursos humanos e materiais causam desmotivação nos profissionais, que, em alguns momentos, passam a atender de forma descuidada, sem envolvimento com as questóes de saúde do usuário, gerando insatisfação em ambos.

Diante de expectativas frustradas, que se repetem consigo, com familiares e amigos, os usuários qualificam o sistema e os profissionais como ineficientes. Ainda que o usuário isente os profissionais de sua parcela de responsabilidade pela má qualidade dos serviços prestados, estes não podem se furtar a disponibilizar recursos pessoais traduzidos pelo acolhimento, atendimento humanizado, vinculação e responsabilização. É uma questáo de ética profissional e respeito à cidadania do usuário. A realização do exame preventivo numa periodicidade maior que a recomendada não traz benefícios e eleva o custo da assistência, diminuindo as oportunidades para outras usuárias.

\section{CONCLUSÃO}

Para as mulheres deste estudo, o itinerário terapêutico rumo à prevençáo do câncer do colo do útero, foi um caminho ora não percorrido, ora trilhado sem continuidade; um caminho delineado ao sabor de oportunidades que surgiram ou ao sabor de oportunidades que se perderam. Às vezes, o caminho foi longo na esperança de um bom atendimento, ou foi perdido à espera de recursos financeiros que lhe garantissem uma escolha confiável. Em todas as formas, foi um caminho que não levou ao ponto de chegada.

A experiência da prevenção foi forjada pelo conceito de saúde e de doença, no qual a saúde é a ausência de doença e a doença é a presença de desordens físicas e psíquicas sensíveis à pessoa. Compreendeu-se que a prevenção para elas é uma ação que se busca diante do sentir-se doente, mediante o surgimento de oportunidades ou em caso de indicação médica. Sentimentos como vergonha e medo da dor foram fatores impeditivos da prevenção.

Visando à reversão desse quadro, é necessário o envolvimento e a compreensão do profissional para acolher a mulher com a sua história de vida, perceber suas fantasias, crenças, tabus e respeitar sua cultura. É necessário orientá-las através da prática educativa, abordando temas relacionados à prevençáo, em que as mensagens devem ser claras, objetivas e numa linguagem adequada aos padróes culturais linguísticos das mesmas. É necessário oferecer-lhes e mostrar-lhes as possibilidades que o sistema de saúde disponibiliza para que possam usufruí-las em prol do alcance de uma melhor condição de saúde. É imperioso que, no nível da atençáo primária à saúde, haja um planejamento em que as açôes do controle do câncer do colo do útero sejam programadas, garantido o acesso, mantendo registros dos exames realizados e promovendo busca ativa para as faltosas, especialmente para aquelas de maior risco.

A prevenção do câncer do colo do útero não está isolada dos demais aspectos da vida da mulher. Decidir fazer ou não fazer não é apenas uma questão de autonomia. A decisão vem mediada pelos contextos em que está inserida, seja ele sociocultural, político, econômico e pelas contínuas avaliações das respostas obtidas no serviço.

\section{CONTRIBUIÇÕES}

Todas as autoras participaram da concepção e planejamento da pesquisa; obtenção, análise e interpretação dos dados; e redação do artigo.

Declaraçáo de Conflito de Interesses: Nada a Declarar. 


\section{REFERÊNCIAS}

1. Instituto Nacional de Câncer (Brasil). Estimativa 2010: incidência de câncer no Brasil. Rio de Janeiro: INCA; c2009. 98 p.

2. Fonseca LAM, Ramacciotti AS, Eluf Neto J. Tendência da mortalidade por câncer do útero no município de São Paulo entre 1980 e 1999. Cad Saúde Pública. 2004;20(1):136-42.

3. Mendonça VG, Lorenzato FRB, Mendonça JG, Menezes TC, Guimarães MJB. Mortalidade por câncer do colo do útero: características sociodemograficas das mulheres residentes na cidade de Recife, Pernambuco. Rev Bras Ginecol Obstet. 2008; 30(5):248-55.

4. Tavares CM, Prado ML. Pesquisando a prevenção do câncer ginecológico em Santa Catarina. Texto Contexto Enferm. 2006;15(4):578-86.

5. Instituto Nacional de Câncer (Brasil). Diretrizes brasileiras para o rastreamento do câncer do colo do útero. Rio de Janeiro: INCA; 2011. 104 p.

6. Martins LFL, Thuler LCS, Valente JG. Cobertura do exame de Papanicolaou no Brasil e seus fatores determinantes: uma revisão sistemática de literatura. Rev Bras Ginecol Obstet. 2005;27(8):485-92.

7. World Health Organization. Manual on the prevention and control of common cancers. Geneva: WHO; 1998. 318 p. (WHO regional publications. Western Pacific series; n. 20).

8. Thuler LC. Considerações sobre a prevenção do câncer de mama feminino. Rev bras cancerol. 2003;49(4):227-38.

9. Oliveira MMHN, Silva AAM, Brito LMO, Coimbra LC. Cobertura e fatores associados à não realização do exame preventivo de Papanicolaou em São Luís, Maranhão. Rev bras epidemiol. 2006;9(3):325-34.

10. Alves PCB, Souza IMA. Escolha e avaliação de tratamento para problemas de saúde: considerações sobre o itinerário terapêutico. In: Rabelo MCM, Alves PCB, Souza IMA. Experiência de doença e narrativa. Rio de Janeiro: Editora FIOCRUZ; 1999. p. 125-38.

11. Martins J, Bicudo MAV. A pesquisa qualitativa em Psicologia: fundamentos e recursos básicos. $5 \mathrm{a}$ ed. São Paulo: Centauro; 2005. 110 p.

12. Bertaux D. Los relatos de vida. Barcelona: Bellaterra; 2005.

13. Instituto Nacional de Câncer (Brasil). TNM: classificação de tumores malignos. 6a ed. Sobin LH, Wittekind Ch, editores; Eisenberg ALA, tradutora. Rio de Janeiro: INCA; 2004. 253 p.
14. Boltanski L. As classes sociais e o corpo. 4a ed. Machado RA, tradutora. São Paulo: Paz e terra; 2004. 179 p.

15. Becker SG, Rosa LM, Manfrini GC, Backes MTS, Meirelles BHS, Santos SMA. Dialogando sobre o processo saúde/doença com a Antropologia: entrevista com Esther Jean Langdon. Rev Bras Enferm. 2009;62(2):323-6.

16. Pinho AA, França Junior I, Schraiber LB, D'Oliveira AFPL. Cobertura e motivos para a realização ou não do teste de Papanicolaou no Município de São Paulo. Cad Saúde Pública. 2003;19(supl 2):S303-13.

17. Carvalho FAM, Pinheiro AKB, Ximenes LB. Assistir à parturiente: uma visão dos acadêmicos de enfermagem. Rev RENE. 2010;11(1):86-93.

18. Chubaci RYS, Merighi MAB. Exame para detecção precoce do câncer cérvico-uterino: vivência de mulheres das cidades de Kobe e Kawasaki, Japão e São Paulo, Brasil. Rev Bras Saude Mater Infant. 2005;5(4):471-81.

19. Secretaria Municipal de Saúde (Belo Horizonte). Prevenção e controle do câncer de colo do útero: protocolos de atenção à saúde da mulher 2008. [Belo Horizonte; 2008]. 22 p.

20. Vale DBAP, Morais SS, Pimenta AL, Zeferino LC. Avaliação do rastreamento do câncer do colo do útero na Estratégia Saúde da Família no Município de Amparo, São Paulo, Brasil. Cad Saúde Pública. 2010;26(2):383-90.

21. Greenwood SA, Machado MFAS, Sampaio NMV. Motivos que levam mulheres a não retornarem para receber o resultado de exame Papanicolaou. Rev LatinoAm Enfermagem. 2006;14(4):503-9.

22. Rafael RMR, Moura ATMS. Barreiras na realização da colpocitologia oncótica: um inquérito domiciliar na área de abrangência da Saúde da Família de Nova Iguaçu, Rio de Janeiro, Brasil. Cad Saúde Pública. 2010;26(5):1045-50.

23. Davim RMB, Torres GV, Silva RAR, Silva DAR. Conhecimento de mulheres de uma Unidade Básica de Saúde da cidade de Natal/RN sobre o exame de Papanicolaou Rev Esc Enferm USP. 2005;39(3):296-302.

24. Ribeiro MGM. Gestante HIV positivo: a história de vida contribuindo para a assistência de enfermagem [dissertação]. Rio de Janeiro: Universidade Federal do Rio de Janeiro; 2000.

25. Cecílio LCO. As necessidades de saúde como conceito estruturante na luta pela integralidade e equidade na atenção em saúde. In: Mattos RA, Pinheiro R, organizadores. Os sentidos da integralidade na atenção e no cuidado à saúde. 4a ed. Rio de Janeiro: IMS/UERJ/ CEPESC/ABRASCO; 2006. p. 113-26. 


\section{Abstract}

Introduction: Brazil has been making increasing efforts to improve the efficiency of cervical cancer prevention programs, seeking to change the high rates of incidence and mortality from this type of cancer; however the measures adopted have not been obtaining the expected results. Objective: This study aims at analyzing the therapeutic itinerary of women with cervical neoplasms focusing on prevention. Method: The qualitative approach and the "Life Story" method, by means of open interview, has been adopted as methodology. The women interviewed were undergoing cervical cancer treatment in a hospital specialized in cancer treatment, located in a city of Minas Gerais. The data were analyzed after theme categorization. Results: Several reasons why most women do not carry out preventive measures have been pointed out. Among them, the concept raised from health, disease and prevention, the lack of information about preventive exams, cultural and social factors facing gender issues, the quality of care and organization of health services were emphasized. Conclusion: It is clear that the issue of prevention is not simply a choice, but a decision involving emotions, experiences, knowledge and circumstances, influenced by the social, cultural, political, and economic contexts and by evaluations of the responses obtained from the service, which are accomplished within the available possibilities.

Key words: Health Care (Public Health); Women's Health; Cervix Neoplasms Prevention; Epidemiology, Descriptive

\section{Resumen}

Introducción: Brasil ha hecho grandes esfuerzos para mejorar la eficiencia de los programas de prevención al cáncer de cuello uterino en el intento de cambiar las altas tasas de incidencia y mortalidad por este cáncer, no obstante las medidas adoptadas no han logrado los resultados esperados. Objetivo: Este estudio, centrado en la prevención, tuvo como objetivo analizar el itinerario terapéutico de mujeres con cáncer de cuello uterino. Método: Se adoptó como trazado metodológico el abordaje cualitativo y el método "Historia de Vida", con entrevista abierta. Las entrevistadas eran mujeres bajo tratamiento de cáncer de cuello uterino en un hospital especializado en el tratamiento de cáncer, ubicado en un municipio de Minas Gerais. Los datos fueron analizados tras categorización temática. Resultados: Los diversos motivos por los cuales la mayoría de las mujeres no realizaron la prevención fueron evidenciados. Entre ellos, se destaca el concepto adoptado como salud, enfermedades y prevención, el desconocimiento sobre el examen preventivo, los factores culturales y sociales frente a cuestiones de género, la calidad del atendimiento y organización de los servicios de salud. Conclusión: Se observa que la cuestión de la prevención no es sólo una opción, sino una toma entre las posibilidades accesibles y que envuelve emociones, experiencias, conocimiento y circunstancias, intermediadas por el contexto social, cultural, político, económico así como por evaluaciones de las respuestas obtenidas en el trabajo. Palabras clave: Atención a la Salud; Salud de la Mujer; Prevención de Cáncer de Cuello Uterino; Epidemiología Descriptiva 